\title{
STATIC VISUAL AIDS -- A DIFFERENT KIND OF TECHNICAL WRITING
}

\author{
Stewart Malcolm
}

\section{Definition}

Static (still) visual aids don't move or produce sound. According to our survey, the most common types are overhead transparencies, flipcharts, chalkboards and slides.

\section{Background}

This paper is based on the research and development of a publication, Trainer's Aid -- Static Visuals. It is the second in a series of "how to" guides for trainers in government departments. Published by the Public Service Commission, this particular Trainer's Aid is applicable to anyone who makes oral presentations and uses static visual aids. We will call these users "presenters"-a convenient generic term.

Nowadays, presenters include anyone from a surgeon explaining an operation to help her patient make a decision, to a manager trying to get his budget through executive committee.

\section{$\underline{\text { Research }}$}

Five sources of information and opinion were tapped during the research phase: a survey of 370 presenters from a variety of disciplines in both the private and public sectors; discussions with audio-visual specialists in two major training organizations; examination of 300 or so static visuals in current use; a review of literature on learning and visual communications; and observations of live presentations.

\section{Focus}

We started out to look at just the design and use of static visuals. However, we soon found that the publication would have to deal with the entire visual environment of presentations. That's because good design and usage could, and probably would, be nullified by any of a number of negative elements, including level of lighting, blocked sightlines, distractions, poor layout of the furniture and equipment, as well as the appearance of the presenter. 
This paper deals only with the design and use of static visuals--a form of technical writing.

\section{Problem Identification}

In reviewing static visuals in current use and observing presentations, we found that anything that could be done wrong, was, and frequently at that. $A$ list of errors in design and use would fill pages. We saw everything from 30 lines of faint typewritten text on one overhead transparency to $35 \mathrm{~mm}$ slides placed backwards in a carousel. In fact, I threw out a set of professionally produced (expensive) overhead transparencies that I had used regularly for several years--just too many errors in design.

Almost without exception, the population surveyed uses some type of static visual aid. Presenters obviously believe that static visuals are the way to go. It's also obvious that most presenters don't understand the role that static visuals should play, nor do they know the basic principles of design and usage.

\section{The Role of Static Visuals}

Technical writing, such as operational manuals, correspondence, reports, etc., is usually a stand-alone communications medium. In an oral presentation, a speaker should be the primary or dominant communication medium. Static visuals should be in a subordinate or support role. They are aids.

That's where presenters go wrong in the first place. All too frequently, static visuals are designed and used in ways that dominate communications with the audience or detract from the presenter's message. In other words, there is competition for the audience's attention, rather than having the visuals complement the presenter.

\section{First Principle}

A static visual should focus the audience's eyes on the point the presenter is making. A static visual should also help the audience situate the point within the presentation. Static visual aids are primarily control mechanisms. Their use recognizes the following: the attention span of the average person is much shorter than the average presentation; the visual sense will generate distractions from almost anything if it is not stimulated in a controlled manner; few presenters can hold an audience's full attention for more than a few minutes. 


\section{Only Control?}

Given that static visuals focus and increase the audience's active attention without usurping the presenter's role, they can improve recall by planting cues in memory; increase recognition through photos and illustrations; clarify processes, systems, etc. through diagrams.

Static visual aids can also speed up consensus or agreement and increase the credibility of the presenter and the presentation. At least that's what a recent study by the Wharton School of Business showed for presentations at business meetings supported by overhead transparencies.

\section{Our Approach}

The Trainer's Aid series is aimed at trainers and other users of training technology who do not have easy access to the support of specialists or sophisticated equipment. As a result, the series deals only with the basic techniques needed by the do-it-yourselfer. In the case of static visual aids, this meant simplicity of design and usage.

\section{Design Techniques}

As noted in this paper, Trainer's Aid--Static Visuals covers the entire visual environment in which presentations take place. Appendix A contains the complete table of contents. Of particular interest to CATTW members are the following design considerations:

- colour - avoid emotional colours such as orange and red, as well as multicolour visuals

- text - use a point system with bullets rather than sentences

- use no more than 6 lines of text per visual

- lettering - use lowercase

- type style - use simple style, such as san serif regular Helvetica

- avoid curlicues, fancy lettering, borders, etc. as they tend to trigger distracting associations much like the Rorschach (inkblot) test

- use a minimum of 18 point for transparencies and slides, and minimum of 2-inch letters for flip charts and chalkboards

- line spacing - use $1 \frac{1}{2}$ spaces 
- illustrations and diagrams - use line drawings, with the minimum detail needed to make the point

- photographs - tightly focus on the subject with as little extraneous detail as possible

- statistics - display as charts with minimum detail.

\section{$\underline{\text { Summary }}$}

Trainers Aid--Static Visuals was developed to help presenters get the best results from their presentations through the support of effective static visuals. Our research identified a basic problem: presenters tend to use design techniques applicable to stand-alone communication media, such as computer screens, manuals and reports. As a result, the presenter and the visual aids compete for the audience's attention.

A second problem is that some presenters are not aware of the distraction of negative elements in the visual environment that are blocking communication. Layout, lighting, and decor are examples of those elements.

Finally, presenters are not generally aware of the basic criteria for the selection, design and use of effective static visual aids.

\section{Conclusion}

Static visuals have become a common communication tool in business, government and the professions. Since the design of static visuals is a form of technical writing, I feel that teachers of technical writing should consider including them in their courses.

\section{ACKNOWLEDGEMENTS AND REFERENCES}

\section{Sources}

People in the following organizations helped in the research for this Trainer's Aid by supplying references: Canadian Police College; Centre for Career Development-Taxation; Health and Welfare Canada; Transport Canada Training Institute; Visual Planning Group of Canada. 


\section{References}

The librarians at the Public Service Commission conducted an exhaustive literature search. A few of the more relevant publications are listed here. In addition, we reviewed over 50 articles from a broad range of periodicals.

1. Anderson, R.H. Selecting and Developing Media for Instruction. Van Nonstrand Reinhold Co., 1983.

2. Baine, David. Memory and Instruction. Educational Technology Publications, 1986.

3. Heinich, Molenda, Russell. Instructional Media. 2nd ed. Macmilan, 1985.

4. Info Line. How to Prepare and Use Effective Visual Aids. American Society for Training and Development, 1984.

5. Locatis, Atkinson. Media and Technology for Education and Training. Charles E. Merrill Publishing Co., 1984.

6. Oppenheim, Kudd, Carroll and Carroll. A Study of the Effects of the Use of Overhead Transparencies on Business Meetings. Wharton Applied Research Centre, 1981.

7. Russel, Peter. The Brain Book. EP Dutton, 1979.

8. Tufte, Edward R. The Visual Display of Quantitative Information. Graphics Press, 1983.

Stewart Malcolm is Principal, The Project Research Group, Ottawa. Research for this paper was conducted by the author before retiving from the Staff Development Branch of the Public Service Commission of Canada. 
Appendix A

Trainer's Aid-Static Visuals

\section{Contents}

$\begin{array}{ll}\text { Introduction } & 6\end{array}$

$\begin{array}{lr}\text { Some Basic Principles } & 12\end{array}$

The Room - Distractions 16

Layout - The Audience and You $\quad 21$

Equipment - Selection and Layout 36

Design -- General 40

Design .. Overhead Transparencies 58

Design -- Flipcharts $\quad 63$

Design - Slides $\quad 69$

$\begin{array}{ll}\text { Design - Conclusion } & 71\end{array}$

$\begin{array}{ll}\text { Using Static Visuals } & 81\end{array}$

Wrap Up $\quad 83$

Acknowledgements and References $\quad 85$ 